\title{
Child-directed and nutrition-focused marketing cues on food packaging: links to nutritional content
}

\author{
Matthew A Lapierre ${ }^{1,2, *}$, Autumn M Brown ${ }^{2}$, Hunter $\bigvee$ Houtzer $^{2}$ and Tyler J Thomas ${ }^{2}$ \\ 'Department of Communication, University of Arizona, 1103 E University Blvd, Tucson, AZ 85721, USA: \\ ${ }^{2}$ Department of Communication Studies, University of North Carolina Wilmington, Wilmington, NC, USA
}

Submitted 23 December 2015: Final revision received 12 July 2016: Accepted 27 July 2016: First published online 9 September 2016

\begin{abstract}
Objective: We tested whether the presence of both child-targeted and nutritionfocused (i.e. parent-targeted) marketing cues on food packaging was associated with the nutritional content of these products.

Design: We conducted a quantitative content analysis of 403 food packages chosen randomly from the supermarket's online portal along with all products ( $n$ 312) from the cereal aisle in a supermarket from the Southeastern USA. We examined main and interaction effects for cues on nutritional content (e.g. energy density, sugar, sodium, fibre).

Setting: A regional supermarket chain in the Southeastern USA.

Results: Tests of main effects indicated that increased presence of nutritional cues was linked to more nutritious content (e.g. less sugar, less saturated fat, more fibre) while the increased presence of child-targeted cues was uniformly associated with less nutritious content (e.g. more sugar, less protein, less fibre). Among the interaction effects, results revealed that products with increased nutrition-focused and child-targeted cues were likely to contain significantly more sugar and less protein than other products.

Conclusions: Products that seek to engage children with their packaging in the supermarket are significantly less nutritious than foods that do not, while product packages that suggest nutritional benefits have more nutritious content. More importantly, the study provides evidence that those products which try to engage both child and parent consumers are significantly less healthy in crucial ways (e.g. more sugar, less fibre) than products that do not.
\end{abstract}

Keywords Child-directed marketing Parent-directed marketing Food packaging Nutritional content
Food shopping with a child can be a difficult experience for parents to negotiate. As previous research has demonstrated, children and their parents often argue about what product would be the best to buy when they are at the store ${ }^{(1-4)}$. One of the reasons for this difficulty is that parents and children are likely working at cross purposes because children are set on getting the product that is fun and is made for 'kid-tastes' while parents are hoping to find a product that promises healthy content for the family ${ }^{(5,6)}$. Consequently, food makers who wish to target the child market are working to appeal to two different sensibilities: they want their food to appeal to children by emphasizing the fun aspects yet they also want their food to appeal to parents by emphasizing the fact that the food is 'good' for children, particularly on their product packaging. With this issue in mind, the current study tested whether food products that target children and their parents via cues on product packaging are less healthy than foods that do not jointly try to target parents and children, as previous research has shown that such foods are not necessarily better for children's diets ${ }^{(7)}$.

While typically less noticed than other types of marketing approaches, the need for food makers to entice consumers in supermarkets via product packaging is crucial, as products must compete for attention among hundreds of possible competitors. Experiments conducted with both children and adults have shown that product packaging does affect consumer attitudes and behaviours ${ }^{(8-15)}$. For example, recent research suggests that parents are significantly more likely to purchase products for their children if the product packaging touts the health benefits of the product, even if that product is less healthy (e.g. higher in sugar, lower in fibre) ${ }^{(12)}$.

With evidence showing that packaging does have an effect on consumers, at issue is whether these types of marketing tactics are linked to nutritional content and if these foods are actually good for children. This is particularly relevant when considering current long-term trends in child overweight, obesity and associated health 
outcomes ${ }^{(16-18)}$. Nutritional analyses indicate that foods which feature more child-targeted marketing cues on the package are less healthy than foods with fewer of these cues ${ }^{(19-22)}$.

In looking at links between nutritional cues and food content, research findings are much more limited. The most exhaustive study examined 56000 food products across six supermarkets in the upper Midwest of the $\mathrm{USA}^{(22)}$. Researchers found that nearly half of all foods had at least one nutrition cue on the package and that half of these products were high in saturated fat, sodium or sugar. Moreover, that study also explored the overlap of child-targeted and nutrition cues, finding that $71 \%$ of products marketed to children also had nutrition cues on the package and of these, 59\% were nutritionally deficient.

Utilizing a content analysis of 715 product packages of foods in an American supermarket, the current study sought to extend these earlier findings in three crucial ways. First, the current study explored potential differential effects linking child-targeted and nutrition cues to nutritional content to determine whether foods that seek to entice children and appeal to parents are less healthy than foods that do not appeal to both of these audiences. Second, rather than looking at the presence/absence of marketing cues as previous studies have done ${ }^{(7,22)}$, the current study looked at the total number of cue types for each to test whether the presence of each additional cue is linearly associated with nutritional content. Lastly, as other research has noted, snacks and breakfast cereals are two of the most heavily advertised foods to children and are less likely to be nutritiously beneficial for children ${ }^{(23-27)}$; as such, the current study oversampled both cereal products and fruit snacks to see if these types of products were different in both nutritional content and the types of marketing cues found on packages.

\section{Method}

The sample of products was collected from one branch of a regional supermarket chain in the Southeastern USA from March to May of 2014. The store operates approximately 100 grocery outlets in North and South Carolina with approximately \$US 1.25 billion in sales annually ${ }^{(28,29)}$. There were two methods used for drawing the sample. First, using the online shopping portal available for this specific store location (e.g. shoppers are able to order their products online and then pick them up at this store), a list of all available food products was generated ( $n$ 21 838). Then, using a randomized sorting procedure, 700 of these products were chosen to be included in the sample; of these, 412 were in the final sample, as the researchers were given a limit on how much time they could spend collecting data by the supermarket and were unable to locate these products. The other part of the sample was comprised of all items located in the cereal aisle at this specific supermarket, which included fruit snacks and cereals. Digital photographs were taken of each product included in the sample. The first set of pictures captured everything on the aisle-facing side of the package. The second set of pictures included the nutrition panel for the food. To ensure that the images were captured appropriately, the images were checked immediately after taking the picture.

\section{Coding procedure}

Product packages were coded for child-targeted marketing and nutrition marketing present. At the outset, it is important to note that the codes for child marketing and nutrition were developed as cumulative measures of both types of marketing approaches, as the presence of more of these cues indicates a more concerted effort to highlight these particular attributes. Development for the childtargeted marketing code was based on previous research $^{(20,30-33)}$. Each package was assessed for the presence of each of the following eight characteristics: (i) child-friendly imagery (e.g. cartoon images); (ii) font (e.g. bubble letters); (iii) tie-ins with other children's media products (e.g. Dora the Explorer mentioned on the package); (iv) premium offers (e.g. promise of a free gift inside the package); (v) presence of a promotional character (e.g. Tony the Tiger, Lionel Messi); (vi) use of child-themed language (e.g. 'Made for kid tastes!'); (vii) product qualities likely to appeal to children (e.g. 'turns your tongue colors!'); and (viii) package convenience (e.g. Lunchables).

The coding procedure for nutrition marketing was guided by previous research ${ }^{(12,13,22)}$, yet also extended previous conceptualizations of nutrition marketing. The coding scheme explored the presence of each of the following cues: (i) nutrient content claims (e.g. 'low in fat'); (ii) health and structure/function claims (as defined by the Food and Drug Administration ${ }^{(34)}$ ); (iii) suggestive brand name (e.g. Lean Cuisine, SmartChoices); (iv) suggestive product name (e.g. Fiber-One); (v) health/nutritionbased comments not stated as a claim (e.g. Simply Nutritious); (vi) health iconography (e.g. images of a heart or tape measure); and (vii) fresh/nutritious imagery (e.g. images of fresh fruits or vegetables).

In order to assess coding reliability, two trained coders both coded $21 \%$ of the sample ( $n$ 150). Kappa reliabilities for child marketing cues ranged from 0.76 for childfriendly font to 1.00 for tie-ins with children's media products; for nutrition cues, the kappa reliabilities ranged from 0.89 for suggestive product name to 0.98 for nutrient content claim. To calculate a score of child marketing and nutrition cues, the total for each of the cues were summed; the scores for child marketing cues could range from 0 to 8 and the scores for nutrition cues could range from 0 to 7 (child marketing cues: mean $=1 \cdot 42 ; 95 \%$ CI 1.29, 1.54; nutrition cues: mean $=2 \cdot 34 ; 95 \%$ CI $2 \cdot 23,2 \cdot 45$ ). 


\section{Nutrition data}

Using the photographs taken from the supermarket data collection, nutrition information was collected for each of the products included in the sample. In situations where there were multiple nutrition profiles (e.g. on cereal boxes that indicate the complete nutrition profile with and without milk), the data collected were based on the 'as packaged' profile. We collected the serving size along with energy, fat, saturated fat, sodium, sugar, protein and fibre (all per serving). In those instances where the nutrition panel indicated that there was less than one unit of measure of any given nutrient, we entered 0.5 for that nutrient. For testing our research questions, we standardized these variables by taking each of the nutrient variables and divided it by the serving size. For example, if a cereal's serving size was $24 \mathrm{~g}$ and the sugar per serving was $8 \mathrm{~g}$, the unit of measure for analyses was $0.33 \mathrm{~g}$ of sugar per gram (another way to think about this is as a ratio of nutrient to serving size; see Table 1 for means and 95\% CI for each variable of interest).

\section{Analysis strategy}

The first step in the analysis included calculating zeroorder correlations for all variables (Table 1). To test main effects for the relationships between marketing cues and nutritional content, ordinary least-squares regression was used. To test interaction effects for nutrient cues and marketing cues, these variables were centred by creating standardized $Z$-scores. Lastly, there were two sets of models tested: the first looked at all foods included in the sample while controlling for whether the product was in the cereal aisle and the second specifically tested all products in the cereal aisle. All analyses were conducted using the statistical software package IBM SPSS Statistics Version 23.0.

\section{Results}

Table 1 shows all zero-order correlations for the variables of interest; of particular note are the relationships between marketing cues and nutritional content. With regard to nutritional cues, there were significant relationships for each nutrient. As the number of nutrition cues increased there was a similar increase in energy density, sugar, fibre and protein content. Conversely, there was a negative relationship for fat, saturated fat and sodium content (i.e. foods had lower sodium content when there were more nutrition cues on the package). When looking at child-targeted marketing cues, these were also all significantly correlated with the nutrition variables. Specifically, increased presence of child-friendly cues was positively linked to energy density and sugar, and negatively linked to fat, saturated fat, fibre and protein. Lastly, there was a significant positive correlation between child marketing cues and nutrition cues, such that as the number of child marketing cues increased, the number of nutritional cues also increased.

Table 2 shows the results of the regression analyses for all products in the sample (while controlling for presence in the cereal aisle). With regard to main effects for childtargeted marketing, when controlling for the amount of nutrition cues, the increased presence of child-friendly cues was linked to decreased fat $(\beta=-0.08, P<0 \cdot 05)$, increased sugar $(\beta=0.22, \quad P<0.001)$, lower protein content $(\beta=-0.22, P<0.001)$ and lower fibre content $(\beta=-0.28, P<0.001)$. In looking at the main effects for nutrition cues, after controlling for child-friendly cues, increased presence of nutrition cues was linked to decreased energy density $(\beta=-0 \cdot 11, P<0 \cdot 01)$, decreased saturated fat $(\beta=-0.17, P<0.001)$, decreased sodium $(\beta=-0 \cdot 11, P<0 \cdot 05)$, decreased sugar $(\beta=-0 \cdot 11, P<0 \cdot 01)$ and increased fibre content $(\beta=0 \cdot 16, P<0 \cdot 001)$. Lastly, the differential effects of child cues and nutrition cues revealed some significant effects. Specifically, the interaction terms were significant for fat content $(\beta=-0.08$, $P<0.05)$, sugar $(\beta=0.11, P<0.01)$, protein $(\beta=-0.08$, $P<0.05)$ and fibre $(\beta=-0.09, P<0.01)$.

When examining the interaction effect for fat content, our results suggested that there was a differential impact regarding the direction of the effect for nutrition and childtargeted cues (see Fig. 1 for a graphical representation for

Table 1 Means, $95 \% \mathrm{Cl}$ and zero-order correlations for variables of interest in the quantitative content analysis of food packages ( $n 715)$ sampled from one branch of a regional supermarket chain in the Southeastern USA, data collected from March to May of 2014

\begin{tabular}{|c|c|c|c|c|c|c|c|c|c|c|c|}
\hline & Mean & $95 \% \mathrm{Cl}$ & 2 & 3 & 4 & 5 & 6 & 7 & 8 & 9 & 10 \\
\hline 1. Cereal aisle† & 312 & $43 \cdot 6$ & $0.52^{\star \star \star}$ & $0.32^{\star \star \star}$ & $0.47^{\star \star \star}$ & $-0 \cdot 15^{\star \star \star}$ & $-0 \cdot 16^{\star \star \star}$ & $-0.09^{\star}$ & $0.45^{\star \star \star}$ & $0.49^{\star \star \star}$ & $0 \cdot 13^{\star \star *}$ \\
\hline 2. Nutrition cues code & $2 \cdot 34$ & $2 \cdot 23,2 \cdot 45$ & & $0.08^{\star}$ & $0 \cdot 16^{\star \star \star}$ & $-0.08^{\star}$ & $-0 \cdot 20^{\star \star \star}$ & $-0 \cdot 12^{\star \star}$ & $0 \cdot 14^{\star \star \star}$ & $0 \cdot 40^{\star \star \star}$ & $0.12^{\star \star}$ \\
\hline 3. Child marketing code & 1.42 & $1 \cdot 29,1.54$ & & & $0 \cdot 15^{\star \star \star}$ & $-0 \cdot 12^{\star \star}$ & $-0.08^{*}$ & -0.06 & $0.36^{\star \star *}$ & $-0 \cdot 11^{*}$ & $-0 \cdot 16^{\star \star \star}$ \\
\hline 4. Energy density & 2.99 & $2 \cdot 88,3.11$ & & & & $0.58^{\star \star \star}$ & $0.37^{\star \star \star}$ & $-0 \cdot 10^{\star \star}$ & $0.40^{\star \star \star}$ & $0.32^{\star \star \star}$ & $0.33^{\star \star \star}$ \\
\hline 5. Fatł & 0.08 & $0.07,0.09$ & & & & & $0.68^{\star \star *}$ & -0.04 & $-0 \cdot 10^{\star \star}$ & -0.001 & $0 \cdot 21^{\star \star *}$ \\
\hline 6. Saturated fat $\ddagger$ & 0.02 & $0.02,0.03$ & & & & & & -0.04 & -0.02 & -0.02 & $0 \cdot 24^{\star \star \star}$ \\
\hline 7. Sodium $\ddagger$ & 0.01 & $0.00,0.01$ & & & & & & & $-0.11^{\star *}$ & $-0.08^{*}$ & -0.06 \\
\hline 8. Sugar & 0.20 & $0.19,0.21$ & & & & & & & & 0.05 & $0 \cdot 21^{\star \star \star}$ \\
\hline 9. Fibreł & 0.04 & $0.04,0.04$ & & & & & & & & & $0.33^{\star \star \star}$ \\
\hline 10. Protein $\ddagger$ & 0.06 & $0.06,0.07$ & & & & & & & & & \\
\hline
\end{tabular}

${ }^{*} P<0.05,{ }^{* *} P<0.01,{ }^{* \star *} P<0.001$.

†n and \% are reported.

¥Nutrient per serving per unit of measure/unit of measure. 
each of the significant interaction effects). Specifically, for food packages that featured more nutrition cues, the fat content decreased as the presence of child-friendly cues increased. Yet, when looking at those products with fewer nutrition cues, the fat content increased as the number of child-targeted cues increased. With regard to sugar content, the interaction effect indicated that, in general, as child marketing cues increased the sugar content increased. However, the change was more dramatic for those foods that featured more nutrition cues; in fact, foods with the most nutrition and child-friendly cues had the highest sugar content. Similarly, the results for both protein and fibre content showed that foods with more child-targeted cues had less protein and fibre. Yet, for foods that had more nutrition cues on the product package, this change was much greater.

The next set of analyses looked just at products in the cereal aisle (see Table 3). Our results for child-friendly cues and nutrient content, while controlling for nutrition cues, revealed a number of significant relationships. Increased presence of child marketing cues was linked to lower sodium $(\beta=-0 \cdot 20, \quad P<0 \cdot 001)$, increased sugar content $(\beta=0.46, \quad P<0.001)$, less protein $(\beta=-0.35$, $P<0.001)$ and less fibre $(\beta=-0.39, P<0.001)$. The link between presence of nutrition cues and nutritional content for products in the cereal aisle, while controlling for childfriendly cues, revealed that increased presence of nutrition cues was associated with lower energy density $(\beta=-0 \cdot 24$, $P<0.001)$, lower saturated fat $(\beta=-0 \cdot 20, P<0 \cdot 01)$, lower sodium $(\beta=-0.32, \quad P<0.001)$, lower sugar $(\beta=-0 \cdot 12$, $P<0.05)$, increased protein $(\beta=0.21, \quad P<0.001)$ and increased fibre $(\beta=0 \cdot 16, P<0 \cdot 01)$.

We then tested for interaction effects to determine whether there was a differential effect for a combination of child-friendly and nutrition cues on foods' nutritional content. We found a significant interaction effect for saturated fat $(\beta=-0 \cdot 15, P<0 \cdot 05)$, sugar content $(\beta=0 \cdot 18$, $P<0 \cdot 01)$ and protein content $(\beta=-0 \cdot 16, P<0 \cdot 05)$. Similar to the results for all foods, we have provided graphical representations to help in interpreting the significant interaction effects (see Fig. 2). For saturated fat content, we found that for products that had fewer nutrition cues, the amount of saturated fat increased as the presence of child marketing cues increased. Conversely, we found that for packaging that had more nutrition marketing cues, the amount of saturated fat decreased as child-targeted cues increased. Regarding sugar content, we found that as child-targeted cues increased the amount of sugar also increased, yet we also found that packages with more child-targeted cues and nutrition cues had the highest sugar content. Our last significant interaction was protein content; here we found that as child-targeted cues increased, protein content decreased. The crucial difference was with nutrition cues for products that did not target children: the protein content was higher for packages that featured more nutrition cues. However, as 

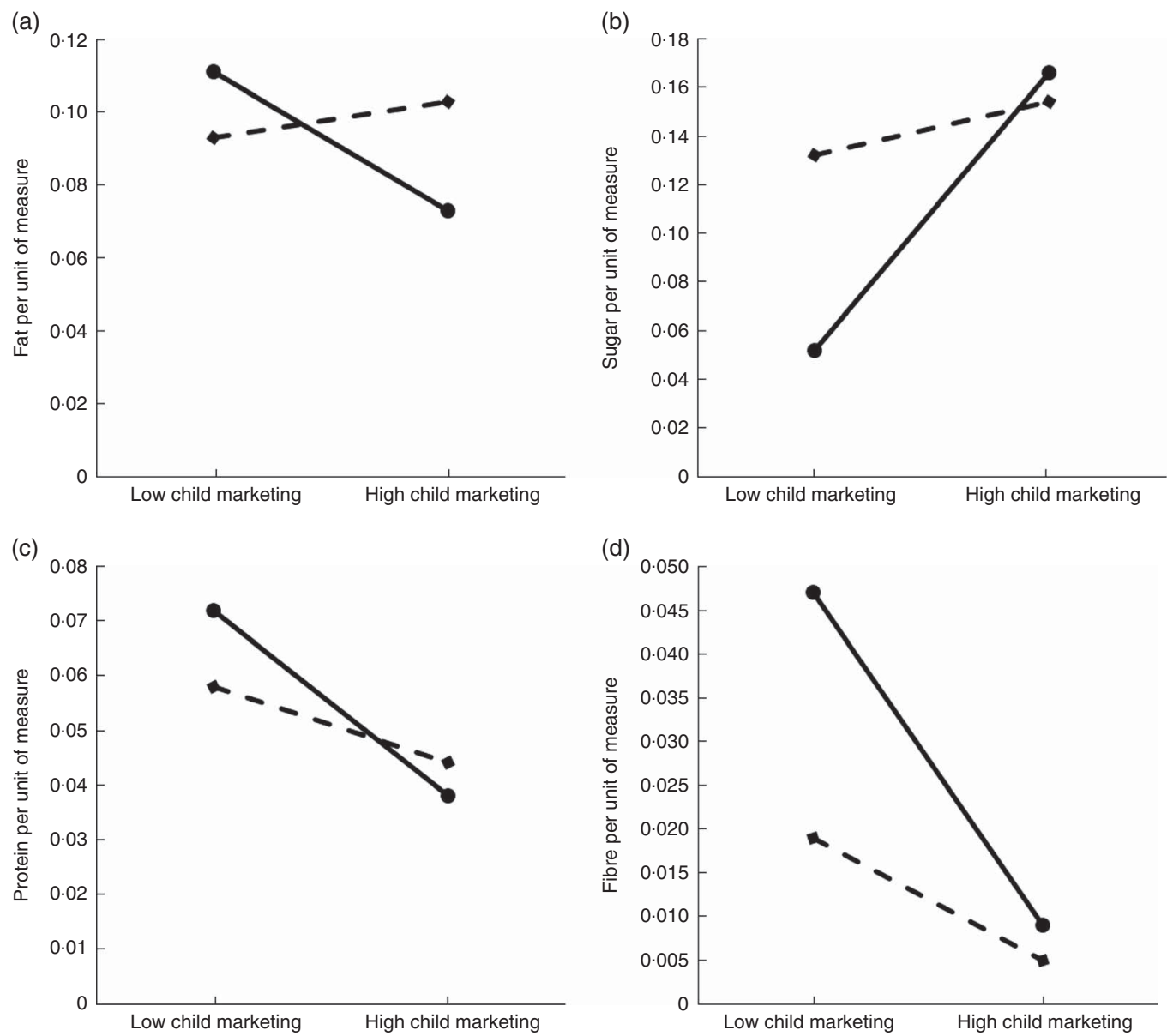

Fig. 1 Significant interaction effects between child marketing cues and nutrition marketing cues ( $\bullet-$, low nutrition marketing; $\longrightarrow$, high nutrition marketing) on (a) fat content, (b) sugar content, (c) protein content and (d) fibre content for all products ( $n$ 715) sampled from one branch of a regional supermarket chain in the Southeastern USA, data collected from March to May of 2014

child cues increased, there was very little difference in protein content based on the presence of nutrition cues.

\section{Discussion}

With previous research demonstrating that foods targeting children, particularly cereals, are less healthy than foods without these cues ${ }^{(19-22,35,36)}$ and that foods which highlight their nutritional content are just as likely to have poor nutritional content as foods that do not ${ }^{(22)}$, the current study extends previous research, most importantly, by exploring the combined use of these marketing tactics and their links to nutritional content and by providing additional evidence that such foods are not uniformly more healthy for children ${ }^{(7)}$. As we discuss in further depth below, when looking across products and specifically products in the cereal aisle, packages that featured more nutrition-based marketing cues (e.g. suggestive brand name, nutrition statements) and child-friendly cues (e.g. promotional characters, tie-ins with media products) had significantly more sugar. Furthermore, we found that the presence of both types of cues was independently predictive of nutritional content in very different ways.

Considering that the average supermarket contains thousands, if not tens of thousands, of individual products for sale, the job of those designing product packages is to make their products stand out to consumers. In the case of capturing the attention of parents purchasing for their child(ren), the product package needs to assure parents that the food they are is considering buying for their child is something that will be healthy and nutritious. The front of the package for a gummy fruit snack needs to sell the parent on the idea that this particular product is made with real fruit, is high in vitamin $\mathrm{C}$, and perhaps highlight its connection to fruit by including that exact word in the product title or a picture of a fresh strawberry on the package. Previous research has shown that such tactics influence the choices both parents ${ }^{(12)}$ and adults ${ }^{(13)}$ make. Conversely, to capture the attention of young shoppers, product packages need to convince children just how fun that product is and to remind them of the products that they have seen advertised on television. So that same package for that same gummy fruit snack will 
simultaneously highlight its wacky flavours, the promise of fun tattoos inside, and images of cartoon characters that appear on that child's favourite television show.

We found that products, whether they were in the cereal aisle or elsewhere in the supermarket, had significantly more sugar and less protein when the packaging seemed to appeal to both parents and children. The findings regarding sugar content support earlier research ${ }^{(7)}$ and are particularly concerning as there are enormous risks associated with increased intake of sugar, especially for children ${ }^{(37-40)}$. Consequently, it appears that makers of higher-sugar foods are trying to walk a fine line between engendering child excitement while also reassuring parents about the product. Furthermore, when looking across all products, we similarly found that products with more child and nutrition marketing cues had less fat and fibre content; while for products in the cereal aisle we found that the increased presence of both sets of cues was linked to less saturated fat and protein content. These findings for fat/saturated fat content are intriguing and support earlier research ${ }^{(7)}$; however, it is not clear whether the lower fat/saturated fat content balances the increased sugar content and lower protein/fibre content.

Surprisingly, when looking at the independent main effects for both types of marketing cues, there were uniquely different findings. Our findings revealed that when simultaneously controlling for child-targeted marketing, the increased presence of nutrition cues was associated with better nutrition content across an array of measures, including lower energy density, fat and sodium content and increased fibre and protein content. The findings from child-targeted marketing cues and nutrition content tell a different story as packages with more of these marketing cues predicted less overall healthy content (e.g. increased sugar, decreased fibre content). While it is important consider the interaction effects when interpreting the main effects, what these findings suggest is that if we look purely at the presence of nutrition cues (after controlling for the presence of child marketing cues), these cues appear to be consistently associated with better nutrition content. In other words, food marketers appear to be accurately matching their cues to consumers with their content.

The most concerning set of findings centre on nutrition content and child marketing cues. While we did not find that child-friendly marketing was pervasive, the mere presence of child-friendly cues was associated with less healthy food content. Furthermore, while previous studies had not tested whether increased attempts (e.g. more cues) to market to children were associated with decreases in nutritional content, the current study found that this is precisely the case as increases in the number of child-friendly cues were associated with linear increases in sugar content along with linear decreases in select protective nutrition content, like fibre content and protein content $^{(19,20,22,35,36)}$. This relationship was found when 

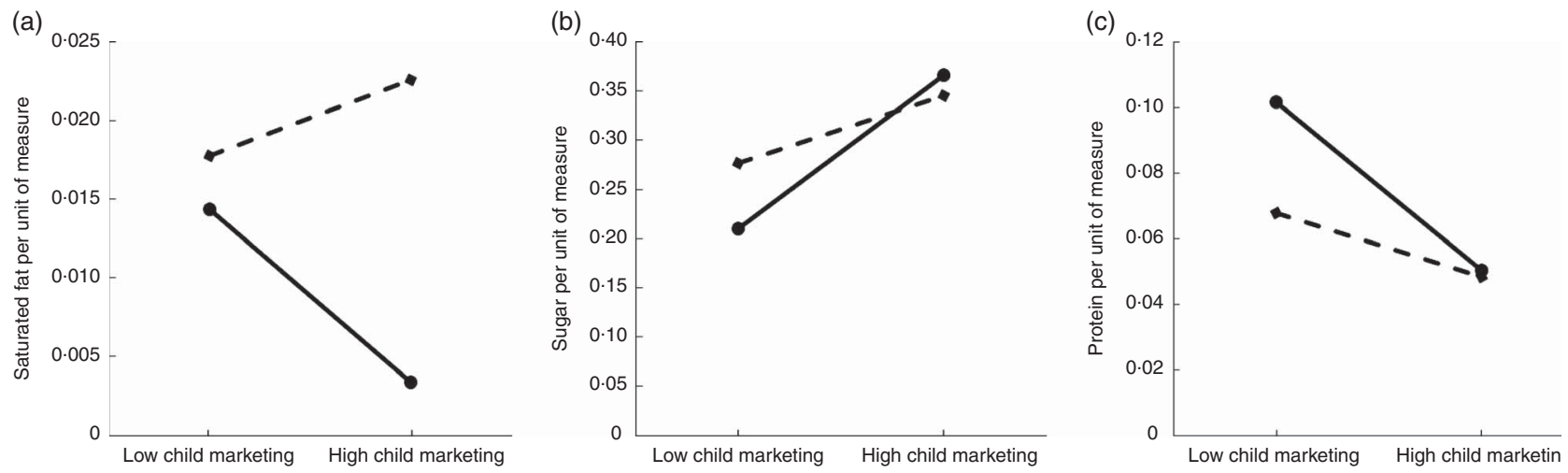

Fig. 2 Significant interaction effects between child marketing cues and nutrition marketing cues ( $\bullet-\rightarrow$, low nutrition marketing; $\longrightarrow$, high nutrition marketing) on (a) saturated fat content, (b) sugar content and (c) protein content for products in the cereal aisle ( $n$ 312) sampled from one branch of a regional supermarket chain in the Southeastern USA, data collected from March to May of 2014

looking at both zero-order correlations and after accounting for the number of nutrition-focused cues.

\section{Implications}

These findings have important implications for public health. With evidence showing that these foods targeting children are less nutritious, we must consider both the immediate and long-term negative health outcomes associated with consuming these foods, particularly foods that are high in sugar ${ }^{(37-40)}$. Moreover, these findings should be considered in light of recent attempts on the part of certain food companies to market healthier foods to children $^{(41,42)}$. It is important to note that while these companies have pledged to change their mediated attempts to sell to children and their nutritional offerings ${ }^{(27)}$, there are no guidelines regarding product packaging, particularly on the use of attractive characters $^{(43,44)}$. In addition, research on these types of child-friendly marketing tactics has consistently shown that these types of packaging features influence children's consumer attitudes and behaviours ${ }^{(9-11)}$. In fact, an expert task force associated with the Robert Wood Johnson Foundation has explicitly called on these member companies to carefully review their marketing practices surrounding product packaging and promotions ${ }^{(45)}$.

The findings reported in the present study suggest that food companies looking to reform their marketing practices to children may want to reconsider how they market to children via product packaging, as the link between child-targeted marketing and poorer nutritional content of foods is consistent. These companies, particularly those that have publicly committed to marketing healthier content in other venues, should limit the use of child-friendly marketing tactics (e.g. cartoon characters, premium offers) on product packaging for those foods that are less healthy for young people.

Similarly, child advocates and public health professionals should apply public pressure to both food makers and governmental agencies to ensure that children are not being targeted inappropriately by these marketing tactics. In addition, parents must be educated about the links between packaging-based marketing tactics and the nutritional content of the foods contained therein. First, they need to know that products which generally target children are typically less healthy. Second, they need to be aware that when those same products tout their nutritional worthiness, they should employ a healthy sense of scepticism.

Lastly, while attempts to use policy to help regulate the marketing industry's targeting of children have historically been resisted by lawmakers (particularly in the USA) ${ }^{(46)}$, there are signs that regulatory agencies have been more willing to pursue changes in how marketers reach both parents and children ${ }^{(47)}$. As such, these findings could help regulators form a more complete understanding regarding how food manufacturers appeal to parents and children and whether such attempts should be watched more carefully. For instance, while this comes from a uniquely different set of products ('educational' baby videos like Baby Einstein), there is evidence that pressure from regulators, researchers and/or parent groups can affect how marketers sell their wares to parents and children when these products suggest outcomes that they cannot actually produce ${ }^{(48)}$.

\section{Limitations}

While one of the strengths of the current study was the use of the supermarket's online shopping portal to select part of the sample, as it allowed us to randomly select products throughout the store, there was some difficulty associated with locating certain products in the sample. It is unclear why exactly this occurred; it may have been a problem with the online shopping portal not matching what the store inventory was, or it could have been an issue associated with time limitations. Specifically, while we were granted permission to collect data in one supermarket, our total time was limited. As such, with more time, we may have been able to locate these products in 
the store but we cannot know for certain. Future research, if equipped with more time and/or financial resources (e.g. actually purchasing the foods in the sample), should try to gather a sample truly at random in order to provide more generalizable insights regarding product packaging.

Future research should also explore a greater diversity of supermarkets. While we reached out to multiple supermarkets to gather data, we were refused by every outlet except one as these supermarkets reported that it was against company policy to allow pictures to be taken of their products. That said, while acknowledging that the supermarket where data collection took place is a smaller chain located in the Southeastern USA, there were no noticeable differences between the products offered in this store and those which the typical shopper would find in larger chain grocery stores.

\section{Conclusion}

Parents face many potential stressors while shopping with children, from dealing with in-store conflict with their children $^{(1,2)}$ to negotiating the tens of thousands of potential choices available in the average supermarket in an attempt to make the best choices for their family. The current study provides evidence that the marketing cues parents and children are likely to encounter on product packaging at the store say quite a bit about the actual nutritional content of these foods. Specifically, while the study supports previous research showing that food packages with more child-friendly marketing cues are more likely to be unhealthy for children ${ }^{(19-21,35,36)}$, the more important takeaway message is that those food packages which feature more child-friendly cues and cues that tout nutritional value are significantly more likely to be higher in sugar, lower in protein (for all products) and lower in fibre (for products in the cereal aisle). As such, our research suggests that policy makers, public health specialists and food producers should look more closely at what is happening on store shelves and these attempts made to compete for consumer dollars, particularly for those foods that simultaneously target both child and parent sensibilities.

\section{Acknowledgements}

Financial support: This research received no specific grant from any funding agency in the public, commercial or notfor-profit sectors. Conflict of interest: None. Authorship: M.A.L. was responsible for formulating the research question, designing the study, helping to carry the study out, analysing the data and writing the article. A.M.B. was responsible for helping to design the study, was primarily responsible for carrying the study out and helped analyse the data. H.V.H. was responsible for helping to design the study, helping to carry the study out and helped analyse the data. T.J.T. was responsible for helping to design the study and carrying the study out. Ethics of human subject participation: Not applicable as the study did not involve human subjects.

\section{References}

1. Atkin CK (1978) Observation of parent-child interaction in supermarket decision-making. J Mark 42, 41-45.

2. Buijzen M \& Valkenburg PM (2008) Observing purchaserelated parent-child communication in retail environments: a developmental and socialization perspective. Hum Commun Res 34, 50-69.

3. Henry HKM \& Borzekowski DLG (2011) The nag factor: a mixed-methodology study in the US of young children's requests for advertised products. J Child Media 5, $298-317$.

4. Haselhoff V, Faupel U \& Holzmüller HH (2014) Strategies of children and parents during shopping for groceries. Young Consum 15, 17-36.

5. Den Hoed RC \& Elliott C (2013) Parents' views of supermarket fun foods and the question of responsible marketing. Young Consum 14, 201-215.

6. Elliott C (2011) 'It's junk food and chicken nuggets': children's perspectives on 'kids' food' and the question of food classification. J Consum Behav 10, 133-140.

7. Elliott C (2012) Packaging health: examining 'Betterfor-You' foods targeted at children. Can Public Policy 38, $265-281$.

8. Vaala SE \& Lapierre MA (2014) Marketing genius: the impact of educational claims and cues on parents' reactions to infant/toddler DVDs. J Consum Aff 48, 323-350.

9. Lapierre MA, Vaala SE \& Linebarger DL (2011) Influence of licensed spokescharacters and health cues on children's ratings of cereal taste. Arch Pediatr Adolesc Med 165, 229-234.

10. de Droog SM, Valkenburg PM \& Buijzen M (2011) Using brand characters to promote young children's liking of and purchase requests for fruit. J Health Commun 16, 79-89.

11. Roberto CA, Baik J, Harris JL et al. (2010) Influence of licensed characters on children's taste and snack preferences. Pediatrics 126, 88-93.

12. Harris JL, Thompson JM, Schwartz MB et al. (2011) Nutrition-related claims on children's cereals: what do they mean to parents and do they influence willingness to buy? Public Health Nutr 14, 2207-2212.

13. Northup T (2014) Truth, lies, and packaging: how food marketing creates a false sense of health. Food Stud 3, 9-18.

14. Robinson TN, Borzekowski DLG, Matheson DM et al. (2007) Effects of fast food branding on young children's taste preferences. Arch Pediatr Adolesc Med 161, 792-797.

15. Levin AM \& Levin IP (2010) Packaging of healthy and unhealthy food products for children and parents: the relative influence of licensed characters and brand names. J Consum Behav 9, 393-402.

16. Ogden CL, Carroll MD, Kit BK et al. (2014) Prevalence of childhood and adult obesity in the United States, 2011-2012. JAMA 311, 806-814.

17. Li C, Ford ES, Zhao G et al. (2009) Prevalence of pre-diabetes and its association with clustering of cardiometabolic risk factors and hyperinsulinemia among US adolescents: National Health and Nutrition Examination Survey 2005-2006. Diabetes Care 32, 342-347.

18. Freedman DS, Khan LK, Serdula MK et al. (2005) The relation of childhood BMI to adult adiposity: the Bogalusa Heart Study. Pediatrics 115, 22-27.

19. Lythgoe A, Roberts C, Madden AM et al. (2013) Marketing foods to children: a comparison of nutrient content between 
children's and non-children's products. Public Health Nutr 16, 2221-2230.

20. Harris JL, Schwartz MB \& Brownell KD (2010) Marketing foods to children and adolescents: licensed characters and other promotions on packaged foods in the supermarket. Public Health Nutr 13, 409-417.

21. Bui M, Kaltcheva VD, Patino A et al. (2013) Front-of-package product labels: influences of varying nutritional food labels on parental decisions. J Prod Brand Manag 22, 352-361.

22. Colby SE, Johnson L, Scheett A et al. (2010) Nutrition marketing on food labels. J Nutr Educ Behav 42, 92-98.

23. Harrison K \& Marske AL (2005) Nutritional content of foods advertised during the television programs children watch most. Am J Public Health 95, 1568-1574.

24. Gantz W, Schwartz N, Angelini JR et al. (2007) Food for Thought: Television Food Advertising to Children in the United States. https://kaiserfamilyfoundation.files.wordpress. com/2013/01/7618.pdf (accessed September 2015).

25. Bell RA, Cassady D, Culp J et al. (2009) Frequency and types of foods advertised on Saturday morning and weekday afternoon English- and Spanish-language American television programs. J Nutr Educ Behav 41, 406-413.

26. Powell LM, Schermbeck RM \& Chaloupka FJ (2013) Nutritional content of food and beverage products in television advertisements seen on children's programming. Child Obes 9, 524-531.

27. Harris JL, Schwartz MB, Brownell KD et al. (2012) Cereal FACTS 2012: Limited Progress in the Nutrition Quality and Marketing of Children's Cereals. New Haven, CT: Yale Rudd Center for Food Policy \& Obesity; available at http://www. cerealfacts.org/media/cereal_facts_report_2012_7.12.pdf

28. Alex Lee, Inc (2009) Lowes Foods, LLC. http://www.alexlee. com/index.cfm/companies/lowesfoods/ (accessed January 2015).

29. Lowes Foods (2014) Company History. http://www. lowesfoods.com/aboutus/history/ (accessed January 2015).

30. Hawkes C \& Harris JL (2011) An analysis of the content of food industry pledges on marketing to children. Public Health Nutr 14, 1403-1414.

31. Chacon V, Letona P \& Barnoya J (2013) Child-oriented marketing techniques in snack food packages in Guatemala. BMC Public Health 13, 967.

32. Elliott C (2008) Assessing 'fun foods': nutritional content and analysis of supermarket foods targeted at children. Obes Rev 9, 368-377.

33. Grigsby-Toussaint DS, Moise IK \& Geiger SD (2011) Observations of marketing on food packaging targeted to youth in retail food stores. Obesity (Silver Spring) $\mathbf{1 9}$ 1898-1900.

34. Food and Drug Administration (2016) Label claims for conventional foods and dietary supplements. http://www. fda.gov/Food/IngredientsPackagingLabeling/LabelingNutrition/ ucm111447.htm (accessed July 2016).
35. Schwartz MB, Vartanian LR, Wharton CM et al. (2008) Examining the nutritional quality of breakfast cereals marketed to children. J Am Diet Assoc 108, 702-705.

36. LoDolce ME, Harris JL \& Schwartz MB (2013) Sugar as part of a balanced breakfast? What cereal advertisements teach children about healthy eating. J Health Commun 18, 1293-1309.

37. Lustig RH, Schmidt LA \& Brindis CD (2012) Public health: the toxic truth about sugar. Nature 482, 27-29.

38. Vartanian LR, Schwartz MB \& Brownell KD (2007) Effects of soft drink consumption on nutrition and health: a systematic review and meta-analysis. Am J Public Health 97, 667-675.

39. Ludwig DS, Peterson KE \& Gortmaker SL (2001) Relation between consumption of sugar-sweetened drinks and childhood obesity: a prospective, observational analysis. Lancet 357, 505-508.

40. Kranz S, Smiciklas-Wright H, Siega-Riz AM et al. (2005) Adverse effect of high added sugar consumption on dietary intake in American preschoolers. J Pediatr 146, 105-111.

41. Council of Better Business Bureaus (2015) Children's Food and Beverage Advertising Initiative. http://www.bbb.org/ council/the-national-partner-program/national-advertisingreview-services/childrens-food-and-beverage-advertisinginitiative/ (accessed December 2015).

42. Kunkel DL, Castonguay JS \& Filer CR (2015) Evaluating industry self-regulation of food marketing to children. $\mathrm{Am} \mathrm{J}$ Prev Med 49, 181-187.

43. Galloway DP \& Calvert SL (2013) Media characters as spokespeople in US grocery stores: promoting poor nutritional messages to children. J Obes Weight Loss Ther $\mathbf{4}, 1$.

44. Council of Better Business Bureaus (2014) Children's Food and Beverage Advertising Initiative: Program and core principles - at a glance. https://www.bbb.org/globalassets/ local-bbbs/council-113/media/cfbai/program-and-coreprinciples_for-online-access.pdf (accessed October 2015).

45. Healthy Eating Research (2015) Recommendations for Responsible Food Marketing to Children. Minneapolis, MN: Robert Wood Johnson Foundation.

46. Kunkel D \& Wilcox B (2012) Children and media policy: Historical perspectives and current practices. In Handbook of Children and the Media, pp. 569-594 [DG Singer and JL Singer, editors]. Thousand Oaks, CA: SAGE Publications, Inc.

47. Federal Trade Commission (2010) FTC investigation of ad claims that Rice Krispies benefits children's immunity leads to stonger order against Kellogg. http://www.ftc.gov/opa/ 2010/06/kellogg.shtm (accessed December 2015).

48. Lewin T (2009) No Einstein in your crib? Get a refund. The New York Times, 23 October, A1. 